\title{
La traducción de Antonio Marqués y Espejo de la Historia de los naufragios (1803-1804): una empresa literariamente instructiva y económicamente provechosa
}

\section{Antonio Marqués y Espejo's Translation of the Historia de los naufragios (1803-1804): a Literary Instructive and Economically Profitable Task}

\author{
Felipe Rodríguez Morín \\ Instituto Feijoo de Estudios del Siglo XVIII \\ felipe.rodriguezmorin@asturias.org \\ ORCID iD: https://orcid.org/0000-0002-6690-7815
}

\section{RESUMEN}

Durante 1803 y 1804 Antonio Marqués y Espejo publicó en cinco volúmenes la Historia de los naufragios, traducción al castellano del libro francés Histoire des naufrages, que su autor galo, Deperthes, había dado a la luz unos cuantos años antes. Con esta colección sobre desastres acaecidos en el mar, además de escoger un tema muy en boga en la época, procuró Marqués inculcar en el lector la correspondiente dosis didáctica que, envuelta en la más amena capa de la intriga y el entretenimiento, juzgaba había de llevar siempre aparejada toda labor literaria; pero, según se desprende del análisis de algunas de sus anotaciones, creemos que su principal aspiración consistió en alcanzar el éxito comercial en la venta de la obra, con la consiguiente ganancia pecuniaria.

Palabras Clave: Marqués y Espejo; Historia de los naufragios; Deperthes; Histoire des naufrages; naufragios; utilidad.

\section{ABSTRACT}

During 1803 and 1804 Antonio Marqués y Espejo published in five books Historia de los naufragios, a translation into Spanish of the French book Histoire des naufrages, which its Gallic author, Deperthes, had written several years before. With this collection about sea-related disasters, apart from choosing a very popular topic at that time, Marqués tried to include an educational part that, covered with such an interesting layer of thriller and entertainment, should be included in every literary work, in his view. However, according to what can be concluded from 
the study of some of his annotations, we think that his main wish was to achieve commercial success by selling books, with the consequent economic profit.

Key words: Marqués y Espejo; Historia de los naufragios; Deperthes; Histoire des naufrages; Sinkings; Utility.

\section{Aparición del libro de Marqués}

Parece ser que en el último día del mes de junio de 1803 se inició la venta del primero de los quince cuadernos que, a razón de tres en cada uno, fueron agrupándose puntualmente en una colección de cinco volúmenes que llevó por título Historia de los naufragios o Colección de las relaciones más interesantes de los naufragios, invernaderos, desamparos, incendios, hambres y otros acontecimientos desgraciados sucedidos en la mar desde el siglo XV hasta el presente, impresos todos ellos en el taller madrileño de Repullés ${ }^{1}$. Tras aquel rótulo, la misma portada daba noticia de la identidad y empleo del traductor hispano: «Publícala en nuestro idioma El Dr. D. Antonio Marqués y Espejo, Presbítero, Pensionado por S. M., y Colector de la Real Casa de Recogidas de esta Corte $\left.^{2}\right\rangle$.

Esta obra de Marqués y Espejo resultaba ser una traducción bastante libre (salvo dos de sus relatos que no figuraban en ella) de la compilación de incidentes marítimos realizada en tres volúmenes por Jean Louis Hubert Simon Deperthes $^{3}$, cuyo tomo primero había sido impreso en París, por Née de la Rochelle, en 1788, y los dos restantes en 1789, con el título de: Histoire des Naufrages, ou Recueil des Relations les plus intéressantes des Naufrages, Hivernemens, Délaissemens, Incendies, Famines, \& autres Evénemens funestes

${ }^{1}$ Los cinco tomos, en octavo, presentaban el siguiente número de páginas: tomo I: «Prefacio»: 14 pp. sin numerar +360 pp.; II: 380 pp. +3 pp. sin numerar, correspondientes al índice del tomo I; III: 384 pp.; IV: 383 pp.; y V: 325 pp.

2 Nacido en Gárgoles de Abajo, provincia de Guadalajara en junio de 1762, contaba entonces Marqués 41 años de edad.

3 Tomo I: «Avertissement de l'editeur» y «Preface» (XVI pp.) + 368 pp. (las dos últimas conforman el índice); II: 407 pp. +3 pp. sin numerar (índice); III: 454 pp. +8 pp. sin numerar (índice, aprobación y privilegio real), al hallarse impreso en $20 \mathrm{~cm}$, en lugar de en octavo como el de Marqués, sus tres volúmenes terminaron valiendo por los cinco de este, y aun muy sobradamente, pues, aunque Marqués incluyó dos episodios ausentes en Deperthes, dejó de traducirle tres; además ha de tenerse en cuenta el crecido número de omisiones observadas en el trasvase lingüístico al castellano. De ahí que, a título de simple ejemplo, podemos referir que si Marqués ocupó 136 páginas en la descripción del primer naufragio, Deperthes necesitó solamente 79 . 
sur Mer, qui ont été publiées depuis le quinzième siecle jusqu à-présent ${ }^{4}$. En esta portada su autor dejaba su nombre enmascarado tras unas iniciales: «M. D. . . , A. . . " [Monsieur Deperthes, Avocat]. A este respecto, ha de significarse que en la primera nota al pie de página que insertaba Marqués, llevada a cabo en la segunda página del «Prefacio», efectuaba la siguiente precisión: «Por la mayor parte hemos seguido para su composición de Mr. D... Avocat, con el mismo título, impresa en París por la última vez en 1800».

Con este «por la mayor parte» estampado por Marqués, probablemente se pretendía significar - aparte de las muchas podas a que lo había sometido, más grandes cuanto más avanzaba la compilación, principalmente en algunas aventuras consideradas por este demasiado largas - las muy contadas ocasiones en las que el sacerdote español se había desviado de su fuente original. A saber: la inclusión de un suceso real acaecido a un buque español el año anterior, con el que cerraba su primer tomo, y el episodio final de la colección, texto refundido de los publicados por varios periódicos nacionales que más adelante nombraremos. Además de ello, prescindió Antonio Marqués de verter al castellano tres naufragios contenidos en el tercer y último tomo de Deperthes: el de la corbeta Betfey en 1756, el del barco Fattyfalam en 1761, y el de madame Godin des Odonais en $1769^{5}$.

Por todo ello hemos de rechazar las opiniones de algunos estudiosos que han juzgado el trabajo de Marqués fruto de la traslación de distintas obras escritas en francés ${ }^{6}$. Tal vez la causa del error estribe en que, por respectivas notas a pie de página, se va nombrando al inicio de cada accidente la fuente impresa de la que se extrajo. Así, a título de ejemplo, traemos lo que se especificaba respecto del primero de los naufragios: «Esta relación fue publicada por Gerardo le Véen en su Verdadera descripción de tres viajes de mar hechos por el Norte, hacia los Reinos de Catay y de la China, en Amsterdam, 1600, en fol. por De Constantin [...]; y por el Abate Prévost en el tomo 15 de la Historia General de viajes, en París, 1759 , en $4^{\circ}$ » (t. I, pp. 1-2). Pero sucede que esa misma observación, que Marqués se limitó a trasladar a su lengua, ya constaba plasmada en el texto de Deperthes; como igualmente hizo el autor

${ }^{4}$ Monique Brosse (1972: 118b) remonta su origen a 1781, con la primera versión de los naufragios de Deperthes, publicada en Reims: Relation d'infortunes sur mer.

${ }^{5}$ Deperthes había distribuido su colección en dos partes bien diferenciadas. En la primera de ellas, que abarca los nueve naufragios de su tomo I, se ocupaba de los desastres de esta índole acontecidos en los fríos mares del norte del planeta, destinando los dos volúmenes siguientes a los siniestros marítimos ocurridos en cualquier otra zona del mundo. Sin embargo, Marqués, que a cuenta de sus previsiones editoriales y del tamaño de los libros incluía menos episodios por ejemplar, únicamente pudo insertar seis de ellos en su primer tomo, teniendo que introducir los otros tres al inicio del segundo, quedando solapada así en alguna medida la más remarcada división del original.

${ }^{6}$ Así lo hace, por ejemplo, Barrio Moya cuando lo considera traducción de varios autores franceses (2005: 361). 
francés en el resto de casos, pues metódica e invariablemente, de un modo u otro, había ido consignando su procedencia prácticamente en la totalidad de las historias ${ }^{7}$; materia esta en la que no deviene tan escrupuloso su intérprete hispano, pues no todas las veces vierte dichas anotaciones al castellano.

Posiblemente sea esa la razón de que Arturo Morgado (2013: 246), aun reconociendo la deuda que de modo especial mantiene Marqués con el mentado libro de Deperthes, indica también que «debe mucho a fuentes francesas, bien originales, bien traducciones, como la Histoire générale des voyages (15 vols., 1746-1759) del abate Prévost, A collection of authentic useful and entertaining voyages and discoveries de John Barrow (3 vols., 1765, y traducidos al francés al año siguiente)». Resultando que, a semejanza de lo que como hemos visto había hecho con Prévost, el susodicho Barrow aparecía también reseñado por Deperthes, y consiguientemente por Marqués, al comienzo de los relatos 3,4 y 5 del respectivo primer volumen de ambos, del francés y de su traductor español.

\section{TRÁMITES PREVIOS A LA PUBLICACIÓN}

En el Archivo Histórico Nacional, Consejos, 5566-44, se conservan varias instancias relativas a esta obra dirigidas por Marqués a la Sala de Gobierno del Consejo de Castilla, a fin de obtener la obligatoria licencia de impresión. La primera de aquellas lleva fecha de 27 de marzo de 1803, y expone el peticionario en ella que: «Se sirva V. A. concederle su facultad y permiso para dar a la imprenta una obra que ha dispuesto, cuyo primer tomo es el adjunto, con el título de: Historia de los Naufragios».

Unas semanas más tarde, Pedro Estala, responsable de la censura del ejemplar, firmará en Madrid, con fecha 15 de abril, un dictamen sumamente favorable. En ese escrito, a la vez que dejaba constancia de su conocimiento del relato original que Antonio Marqués había vertido al castellano, resaltaba lo beneficioso que habría de resultar un libro de esas características que pudiese servir, en cierto modo, de aleccionamiento a la marinería española y prevenir futuras calamidades:

La obra francesa es muy curiosa e importante, pues contiene una relación muy circunstanciada de los naufragios más interesantes acaecidos en estos últimos siglos, lo cual será de la mayor utilidad para nuestros navegantes, ya para evitar semejantes desgracias, ya para conducirse con acierto, si se hallaren en igual caso.

${ }^{7}$ Como excepción solo hemos hallado el relato $n^{\circ} 11$ del tomo II, «Naufrage Du Vaisseau Hollandois le Coromandel, dans le Golfe de Bengala, en 1660», en donde no se cita el origen del mismo. 
De otra parte, revelaba Estala en su informe una opinión muy positiva acerca del menester ejercido por Marqués y Espejo para trasladar su texto del francés: «El traductor manifiesta claramente en la versión de este primer cuaderno no solo que posee perfectamente ambos idiomas en términos de darnos una traducción fiel, y en estilo puro y correcto, sino que es capaz de corregir cualquier defecto que se hallase en el original»».

Como además, por tratarse de materias históricas, se hallaba lejos este título de colisionar con cuestiones tocantes a la religión o a las leyes, concluía el escolapio evaluador, sin motivos de oposición, reiterando nuevamente lo provechoso de autorizar su difusión: «Por todo lo cual soy de parecer que la publicación de esta obra será muy útil al público; lo que participo a Vm. para que lo ponga en noticia del Consejo»; y por fin el 9 de mayo obtuvo la aprobación del Consejo, si bien con la prevención de que la impresión, a causa de la temática tratada, había de ser dirigida por el Ministerio de Marina. Por tal motivo, hubo de conseguir un permiso adicional de dicho departamento, que terminó verificándose el día 2 de junio. Sin pérdida de tiempo, en el día siguiente se apresuró Marqués, con el fin de materializar prontamente el proyecto, a efectuar el oportuno ingreso de 60 reales en la Real Caja de Descuentos de Madrid.

Conviene ahora que nos detengamos, siquiera brevemente, a tratar de discernir la diferente terminología utilizada por el autor y el censor en cuanto a la obra objeto de examen. Puesto que, tal y como hemos más arriba transcrito, la denominaba como «tomo» aquel y como «cuaderno», en cambio, este. Esa discrepancia, que en otro caso fuera baladí, no lo es tanto en el presente, puesto que el propósito de Marqués era ir dando a la luz su traducción por entregas — «que como todas es de ocho pliegos» («Prefacio, s.n.») — , esto es cuaderno a cuaderno, para agruparlos posteriormente de tres en tres en cada volumen. Probablemente sucedió que el ejemplar aportado para conseguir el permiso de impresión fuera realmente un tomo, que desde luego no tendría por qué coincidir con el que más tarde acabó en letra de molde, sino que suponemos que resultaba incluso más extenso, de ahí que bajo solo tres peticiones de licencia se cobijaran los cinco tomos definitivos. La locución que emplea Estala quizá viniera en este caso de algún modo mediatizada por lo que leyó al principio de aquel si es que, conforme a su plan de sacarlos sueltos, Marqués había transcrito, tras el título general, el rótulo de «primer cuaderno».

El hecho cierto es que antes de alcanzar la aprobación del Consejo de Castilla en la siguiente cita con la censura, el 22 de julio de 1803, ya había salido a la luz la segunda entrega, conforme lo atestigua la Gaceta de Madrid :

${ }^{8}$ Gaceta de Madrid de 15 de julio ( $\mathrm{n}^{\mathrm{o}}$ 56, p. 612): «El cuaderno $2^{\circ}$ de la Historia de los naufragios (que contiene el fin o conclusión de la relación de la primera entrega, con otras dos relaciones que son de las más interesantes) se hallará desde el día de hoy en la librería nueva de la calle de Jacometrezo, y en la de Gomez Fuentenebro, en la de las Ca- 
Por otro lado, en el propio expediente de licencia de impresión Bartolomé Muñoz de Torres, secretario de S. M. y escribano de cámara y de gobierno, alude al ejemplar presentado como «tomo primero», y se recordaba también en este mismo despacho una real disposición de 1798 que obligaba a todos los papeles que tratasen de la profesión militar y pretendiesen ser publicados a que tuvieran que recibir del monarca la real licencia, puntualizando que en el caso presente resultaba necesaria porque pudiera «tener conexión con la materia de Marina».

Tal consideración refuerza aún más la idea de que lo presentado a la censura no fue un solo cuaderno, sino un conjunto de ellos, si lo enlazamos con el hecho de que entre ellos sin duda se encontraba el relato perteneciente a un buque español en el año 1802, esto es, un año antes de las fechas de las que hablamos, y que posiblemente fue el episodio causante del beneplácito específico que hubo de otorgar el soberano. En la versión puesta de molde dicho incidente fue colocado al final del tomo primero, como «Adición a este primer tomo. Breve noticia del naufragio de la Gabarra Española la Ferrolina en las Costas de la China en 1802». El Diario de Madrid de 20 de agosto de 1803 $\left(\mathrm{n}^{\mathrm{o}} 232\right.$, p. 930), en un anuncio redactado seguramente por Marqués, se hacía eco de ese suceso:

El cuaderno tercero de la historia de los naufragios, con el cual concluye el tomo primero, y en el que se ha insertado como por suplemento el mismo cuaderno, para no interrumpir el orden cronológico, el naufragio de nuestro buque español la ferrolina o ferroleña sucedido el año pasado (802) en las costas de la China a unas cuarenta leguas de $\mathrm{Macao}^{9}$.

Con lo que, de ser dicha hipótesis cierta, y el origen del permiso especial la inclusión del percance de La Ferrolina, quedaría acreditada la confusión de Estala al señalar como primer cuaderno el texto a examinar.

Ese equívoco hubiese sido bien sencillo de deducir sin falta de tanta minuciosidad argumental, si no fuera porque la cosa lejos de terminar ahí prosiguió complicándose todavía más desde el momento en que se llevó la continuación del libro a la preceptiva inspección, pues ya no será únicamente Estala quien lo llame cuaderno, sino que el propio Antonio Marqués en su solicitud, fechada el 6 de julio de 1803, exponía lo siguiente: «Con todo respeto dice que, en continuación de la obra que ha empezado a publicar titulada Historia de los Naufragios, ha traducido el segundo cuaderno, que presenta». En consonancia

rretas». Igualmente, el Diario de Madrid de 27 de julio de 1803 (n 208: 284) abundaba en la noticia: «El segundo cuaderno de esta obra se halla en la librería nueva de la calle de Jacometrenzo [sic][...]; y se previene que está abierto el término del menor precio del cuaderno primero hasta el último día del presente mes».

9 En parecidos términos se había expresado la Gaceta de Madrid de 16 de agosto de $1803, \mathrm{n}^{\circ} 65: 712$. 
con ello, Pedro Estala, el 13 de ese mismo mes, replicaba diciendo que: «he examinado el cuaderno segundo de la Historia de los naufragios, y no he hallado en él cosa contraria a la Religión, buenas costumbres, leyes del Reino y regalías de S. M.; y siendo por otra parte muy útil e instructiva esta obra, no hallo inconveniente para su impresión». Por su parte, la Sala de Gobierno del Consejo, contagiada de la expresión, autorizó el 22 de julio la impresión del «cuaderno $2^{\circ}$ de la Historia de los naufragios. Y, por último, el 1 de agosto Marqués realizó el consiguiente ingreso de 60 reales en la Real Caja de Descuentos de Madrid, por el «cuaderno $2^{\circ}$ de la obra que está traduciendo, titulada Historia de los naufragios».

Extraña, desde luego, que sea el mismo autor quien denomine como «cuaderno» algo distinto a lo que con ese mismo nombre estaba comercializando justo en aquellos momentos en las librerías, a no ser que se guardara muy bien de pretender enmendar la plana a aquellos de los cuales, precisamente, dependía el que ulteriores ventas continuasen produciéndose. Es decir, que como le había ido bien la primera vez, ¿por qué tener que rectificar ahora a nadie? ${ }^{10}$

${ }^{10} \mathrm{Y}$ así, entre esa segunda aprobación y la tercera y definitiva, que había de ocurrir en octubre, fueron alumbradas, según testimonio de los periódicos madrileños la Gaceta y el Diario, las entregas siguientes: «El cuaderno $4^{\circ}$ de la Historia de los naufragios, con que empieza el tomo $2^{\circ}$ y las Relaciones de los rusos en sus descubrimientos marítimos» ( $\mathrm{Ga}$ ceta de Madrid de 9 de setiembre, $\mathrm{n}^{\circ}$ 72: 788); «La entrega cuarta y primera del tomo segundo de esta obra se halla en la librería [...]; como también el primer tomo» (Diario de Madrid de 16 de setiembre de 1803, $\mathrm{n}^{\circ}$ 260: 1039). Con motivo del aviso del cuaderno quinto (Gaceta de Madrid de 23 de setiembre, $\mathrm{n}^{\circ}$ 77: 836), el Diario de Madrid de 5 de octubre ( ${ }^{\circ}$ 279: 1114) aprovechó para anunciar otras dos obras de Marqués el Diccionario feijoniano y Blanca Capello. De la aparición de los siguientes dos folletos, $6^{\circ}$ y $7^{\circ}$, se hizo eco la Gaceta de Madrid de 14 de octubre y 1 de noviembre, respectivamente (números 83 y 88: 896 y 948), con la prevención en el primero de los casos de que en las librerías donde se podían adquirir (siempre las mismas: en la llamada «librería nueva» de la calle de Jacometrezo y en la de Gómez Fuentenebro): «se venderá a real la estampa que deberá colocarse en el núm. $\mathrm{I}^{\mathrm{o}}$ de esta obra». El aviso del séptimo cuadernillo fue difundido también por el Diario de Madrid de 7 de noviembre de 1803, $\mathrm{n}^{\circ}$ 312: 1247. Por su parte, las restantes entregas de Marqués fueron anunciadas en las fechas siguientes: la número 8: Gaceta de Madrid de 22 de noviembre de 1803, $\mathrm{n}^{\circ}$ 94: 1012, y Diario de Madrid de 23 de noviembre de 1803, $\mathrm{n}^{\circ}$ 328: 1310-1311; $\mathrm{n}^{\circ}$ 9: Gaceta de Madrid de 9 de diciembre de 1803, $\mathrm{n}^{\circ}$ 99: 1063, y Diario de Madrid de 14 de diciembre de 1803, $\mathrm{n}^{\circ}$ 349: 1397-1398 («con él concluye el tercer tomo»); $\mathrm{n}^{\circ}$ 10: Diario de Madrid de 21 de diciembre de 1803, $\mathrm{n}^{\circ} 356: 1427$ («es el primero del tomo cuarto»); $\mathrm{n}^{\circ}$ 11: Diario de Madrid de 21 de enero de 1804, $\mathrm{n}^{\circ}$ 21: 82; $\mathrm{n}^{\mathrm{o}}$ 12: Gaceta de Madrid de 3 de febrero de 1804, $\mathrm{n}^{\mathrm{o}}$ 10: 112 («con que concluye el tomo $\left.4^{\circ} \gg\right)$, y Diario de Madrid de 11 de febrero de 1804, $n^{\circ}$ 42: 166; $\mathrm{n}^{\circ}$ 13: Gaceta de Madrid de 14 de febrero de 1804, $\mathrm{n}^{\mathrm{o}}$ 13: 144, y Diario de Madrid de 20 de febrero de 1804, $\mathrm{n}^{\circ}$ 51: 202-203 («El cuaderno 13 de la Historia general de los Naufragios, con que empieza el tomo quinto, y último de esta obra»); $\mathrm{n}^{\circ}$ 14: Gaceta de Madrid de 28 de febrero de 1804, $\mathrm{n}^{\mathrm{o}}$ 17: 188 ( «El cuaderno 14 de la Historia general de los naufragios, penúltimo de toda la obra») y Diario de Madrid de 7 de marzo de 1804, $\mathrm{n}^{\circ}$ 67: 266. Y, finalmente, el $\mathrm{n}^{\circ}$ 15: 
Las gestiones para la tercera y última petición de licencia para imprimir fueron iniciadas por Antonio Marqués el 10 de octubre de 1803, a través de un escrito en el que el suscribiente a duras penas podía contener su satisfacción por el éxito que estaba logrando su iniciativa entre los lectores: «deseoso de corresponder debidamente a la aceptación general que hasta ahora se le ha dispensado». Una vez más será Estala el encargado, y nuevamente su dictamen de 22 de octubre resultará favorable, y aun elogioso, pues además de no contener impedimento para su difusión, y siendo «muy importantes sus noticias para la navegación y para otros objetos», «juzgo que su publicación podrá ser muy útil al público». De ahí que, poco después, el día 26 obtenga la autorización del Consejo, y el 3 de noviembre fueran abonados los pertinentes 60 reales. Curiosamente, en esta ocasión ninguno de los intervinientes, esto es, ni el solicitante, ni el censor, ni la Sala, ni el empleado de la Caja de Descuentos hará mención a la palabra «cuaderno ${ }^{11} 》$, siendo así que es siempre y por todos ellos nombrado como «el tomo de la Continuación de la Historia de los naufragios $^{12} \gg$.

\section{Principales objetivos en la obra de DePerthes}

En el inicio del libro del escritor francés aparecía un «Avertissement de l'éditeur», que Marqués no trasladó a la versión española, sino que únicamente lo recompuso en alguna medida en su «Prefacio», o luego más tarde en el Diario de Madrid de 10 de abril de 1804, según hemos de ver. Se reconocía allí en esa «Advertencia» que la colección que presentaba había sido el fruto de más de 20 años de trabajo por parte del autor, de sus lecturas en diversas

Gaceta de Madrid de 16 de marzo de 1804, $\mathrm{n}^{\circ}$ 22: 248, y Diario de Madrid de 10 de abril de ese 1804, $\mathrm{n}^{\circ}$ 101: 400-401, anuncios estos dos últimos en los que más por extenso nos detendremos en su momento.

${ }^{11}$ A pesar de lo anteriormente expuesto, Arenas Cruz (2003: 498 y 499) se refiere a cada uno de los tres textos objetos de informe por el censor Pedro Estala como «cuadernos».

${ }^{12}$ Existe un ejemplar manuscrito de la Continuación de la historia de los naufragios en AHN, Consejos, 5795, exp. 6, que posiblemente fue el presentado a la censura. Se trata de un manuscrito de unos 70 folios en $4^{\circ}$, con desorden en su numeración, y que comienza in media res con letra minúscula: «el Lector si son unos trabajos, los más despreciables del género humano, como los primeros navegantes que llegaron al cabo quisieron manifestarnos [...]», en evidente prosecución de un texto anterior. Al final del libro figura la firma del antes mencionado escribano Bartolomé Muñoz, y en algunas hojas aparecen rayas tachando párrafos, si bien pudieran ser obra del propio autor, pues muchos de esos pasajes se corresponden con notas geográficas, ajenas por completo a cualquier contenido ideológico. Ha de destacarse, asimismo, el hecho de que esta obra termina con el mismo relato que la de Deperthes, es decir, carece del episodio agregado por Marqués tocante al amor traicionado de la india Yarico, que más adelante examinaremos. 
bibliotecas, y especialmente en la suya propia, una de las más completas, según se manifestaba, en materia de descripciones de países lejanos y viajes marítimos. Puntualizaba igualmente el editor — que conjeturamos podía ser el propio Deperthes - que si bien este en un principio no había puesto límite al número de episodios, posteriormente por diversos motivos los había reducido, al menos por el momento, a cuarenta; y aducía que había rechazado varios de aquellos relatos por increíbles, repugnantes, o carentes de una finalidad instructiva o de interés para el «Lecteur délicat», marginando también de la colección todos los relatos que presentaban un carácter novelesco o contrario a la verdad.

A esta «Advertencia» le sucedía un «Preface», que no solo fue enteramente trasladado por Marqués, sino que le añadió unos cuantos párrafos de su propia cosecha, resultando un total de 14 páginas, sin numerar, entre las que también incluyó alguna información sobre el contenido de la colección que ya avanzaba el mencionado «Avertissement de l'éditeur»; siendo así que podemos dividirlo en dos partes claramente diferenciadas, y que estudiaremos por separado.

Ateniéndonos a la primera de ellas, es decir, a la traducida de la fuente francesa, un concepto quedaba en el «Prefacio» realzado por encima de cualquier otro, puesto que se hacía constar que aquella colección de desgracias acontecidas en la mar había sido confeccionada «con la intención misma de inspirar el sentimiento y beneficencia [...], inclinaciones propias de los corazones virtuosos, y por las cuales como que están ligados a la humanidad». Y al objeto de producir esos efectos en el destinatario resultaba de enorme importancia la sensación de verdad que la obra tenía que transmitir. En este orden de cosas, se subrayaba por parte del autor galo, y por ende de Marqués, el hecho de que aun en el terreno de la literatura de ficción los sucesos lamentables provocaban sentimientos en el lector, ya que «en la representación de un drama trágico, igualmente que en la lectura de una novela, la compasión y la ternura le arrancan las lágrimas»; por eso, cuánto más no iban a tener lugar esas emociones tratándose de un acontecimiento real. Y no únicamente tal circunstancia concurría aquí, pues el narrador no se limitaba a conducirse como un historiador, que «casi siempre se refiere al testimonio de otro», sino que era en realidad el protagonista absoluto del lance, esto es: el navegante, de ahí que al resultar «más verídico y sencillo en su relación, y con menos miras [...], tenemos al leerle una especie de interés y curiosidad, que nos identifica con él». Por tal motivo se complace mucho el autor en proclamar de su obra que «es la misma verdad su principal fundamento».

Destacaba también Deperthes algunos aspectos positivos que, desde un punto de vista humano, se derivaban de la lectura de la obra, pues con el conocimiento de tan funestos avatares podrían los desgraciados alcanzar «un justo motivo de consuelo», y de su conjunto un compendio de posibles remedios para aquellos que lamentablemente en un futuro sufriesen algún infortunio similar. Esta consideración de la colección como un argumento para el ejemplo 
se veía reforzado con el anuncio, en síntesis de ello, de cinco casos concretos que se pintaban como modelo de heroicidad, virtud y resignación cristiana, cuatro de ellos personificados en mujeres ${ }^{13}$. Como así fue el caso, por indicar solo uno, de Leonor García Salas, «enterrándose viva en la arena por pudor y ternura maternal ${ }^{14} \gg$.

Esta parte del prólogo se hallaba, en fin, por completo impregnada de unos conceptos y de un vocabulario tocante a los sentimientos humanos, muy propio de fines del siglo XVIII, pero que podían parecer, en principio, alejados del imperio de la razón con el que tan bien parecía avenirse el espíritu ilustrado; sin embargo, como apunta Froldi (1984: 59): «el hallazgo de la sensibilidad y el reconocimiento del sentimiento como modalidad fundamental, junto con la razón, de la naturaleza humana, provienen de la Ilustración». De ahí que Deperthes se encargue de enfatizar este tipo de vivencias en su «Prefacio», cuando proclama que el libro: «presentará a las almas sensibles una galería de cuadros tiernos», con la idea en mente de convertir las almas indiferentes e impasibles en seres compasivos y solidarios con las desdichas ajenas: «ojalá que consigamos el saber que siquiera un solo espíritu de los insensibles se ha determinado después de la lectura de esta colección a aumentar el número de los hombres virtuosos y bienhechores, dichosos partidarios de la triste humanidad ${ }^{15} \gg$.

Una importante contraseña que probaría la inmersión en ese universo emotivo lo constituía, sin duda, la acción de llorar. Así, Deperthes confiesa que ello ya ha ocurrido con anterioridad a dar su texto a la imprenta, pues habiéndoles facilitado algunos episodios a sus amigos, «han ocasionado ya en su lectura el género de emociones repentinas y de lágrimas dulces... Pero ¡y quién podría ser tan insensible que no las llegase a derramar a vista de los esfuerzos de la industria humana». Y algo más adelante añade: «iAh! ¡lágrimas de ternura! ¡qué recompensa tan lisonjera!».

Junto a este asunto concerniente al ámbito recóndito de la intimidad, se desplegaba otro elemento propio de este período, pero abierto, en cambio, completamente al mundo exterior, cual fue el de la naturaleza, y la nueva pers-

${ }^{13}$ Esa preferencia tuvo que ser muy del agrado de Antonio Marqués, quien a lo largo de su carrera literaria dio muestras de una especial preocupación por las dificultades añadidas que soportaba el mundo femenino; afán este suyo tal vez surgido o potenciado a raíz de haber ejercido de colector en la Real Casa de Acogidas de Madrid.

14 Para Pérez-Mallaína (1997: 58) este pasaje fue novelado, y cree que los hechos de ninguna forma ocurrieron así, sino que Leonor moriría de insolación o de otra suerte de desgracia, y sostiene que la protagonista había hecho lo que dictaba la mentalidad de la época acerca del pudor femenino.

15 Sánchez-Blanco (1986: 39) observa al efecto: «Poseer un corazón "sensible" es considerado tan importante por los hombres de finales del siglo XVIII como la idea del bien común». 
pectiva con la que aparece contemplada ${ }^{16}$; una naturaleza que precisamente se muestra aquí en su vertiente más dura y cruel, y que se convierte en el desencadenante de toda una serie de desgracias que dan soporte a la obra, en un marco temático concreto sumamente frecuente en aquellos años, puesto que como indica Arturo Morgado: «durante la Ilustración y el Romanticismo, muy en la línea de los movimientos prerrománticos con su afán por presentarnos la grandeza y la inmensidad de una naturaleza indomable, hay un creciente interés por el tema del naufragio» (2013: 230).

El éxito extraordinario que supuso Robinson Crusoe a lo largo de todo el siglo XVIII, y sobre todo el notorio aumento de siniestros navales consecuencia estadística de un intenso incremento en la actividad mercantil, científica, etc., llevada a cabo a través de la navegación ${ }^{17}$, condujeron a un creciente interés de la literatura por esa clase de percances marítimos, hasta el punto de que «el número de obras que desarrollan el tema del naufragio es pavorosamente ingente $\left.{ }^{18}\right\rangle$.

Por otro lado, era esta una materia que se prestaba a interpretar no solo de una forma real, sino también en un sentido abstracto o simbólico, en donde los peligros del mar resultaban un trasunto de los que el hombre debía arrostrar y superar durante la travesía de su vida ${ }^{19}$. Hemos de recordar al efecto que ya el protagonista de Telémaco, obra de tan colosal ascendiente durante todo el siglo XVIII, se había encargado de establecer esa suerte de paralelismo en 1699: «Ya no temo al mar, ni a los vientos, ni a las tempestades; nada temo ya sino a mis

${ }^{16}$ Pues, como dice Ballesté (1998: 36): «En la literatura también se reflejó el impacto de esta nueva visión de la naturaleza capaz de secundar la expresión de sentimientos y apta para desempeñar un protagonismo relevante en la creación literaria». Englobando unos y otros aspectos, Aguilar Piñal, en sustitución del término «prerromanticismo» o «primer romanticismo», acuña el sintagma neoclasicismo sentimental para designar todo aquel tipo de obras «en que se vierten lágrimas en abundancia y el alma se estremece ante la soledad o el infortunio del prójimo y se siente sacudida por el atractivo irresistible del alma noble y virtuosa o por el espectáculo de la naturaleza, a veces sosegada y amable, a veces inmisericorde y terrorífica, pero siempre atrayente en su insondable misterio» (1991: 208).

17 A este respecto, Esperanza Guillén apunta lo siguiente: «A lo largo del siglo se produce un elevado número de tragedias náuticas. La necesidad del desplazamiento marítimo por causas comerciales, de conquista, exploradoras, o simplemente por el placer o la necesidad del viaje hacen que haber experimentado una tempestad, como Goethe, sea algo habitual; como será relativamente frecuente la muerte de algún conocido en el mar» (2004: 12).

${ }^{18}$ Esperanza Guillén (2004: 13). Ya Álvarez Barrientos había comentado dicha circunstancia con anterioridad: "son muchas las novelas dieciochescas en las que el naufragio es episodio obligado y que, cuando aparece, las semejanzas entre unas novelas y otras son muchas» (1991: 244).

${ }_{19}$ El Diccionario de Autoridades presentaba como segunda definición de la palabra «naufragio» la que sigue: «Metafóricamente vale pérdida grande en cualquier línea, desgracia o desastre» $(1734, \mathrm{t}$. IV). 
pasiones: el Amor por sí sólo es más temible que todos los naufragios» (Fénelon 1932: 155).

Por su parte, Ana Rueda (2001: 428) explica que «los textos ilustrados recalan en imágenes de desastres marítimos con el objeto de iluminar los reveses de la Fortuna y la necesidad de ser prudente y esforzado sin dejarse arrastrar por las pasiones». Y unas pocas líneas después añade: «la tesis religiosa latente en las narraciones de naufragios en torno a 1800 es que el cielo no desampara a la virtud perseguida y que la Providencia, tarde o temprano, acude al socorro del inocente». Tal circunstancia la encontramos gráficamente constatada en la obra de Deperthes y, casi literalmente trasladada del texto del francés (t. II: 293), aparece asimismo en el de Marqués, que al igual que aquel entrecomilla la siguiente reflexión de Gauitier Schouten, de quien, en definitiva, se había tomado la historia: «Los ruegos del cristiano (dice con razón Schouten) nunca dejan de ser oídos. Los de estos desgraciados llegaron hasta el cielo; Dios fortificó su ánimo, y les inspiró la idea de seguir la costa oriental» (t. IV: 15-16).

\section{Principales objetivos de Antonio Marqués}

A pesar de todos esos presupuestos teóricos acerca del hombre sensible, de sus lágrimas y melancólicas reflexiones, o bien sobre las nuevas consideraciones respecto de la naturaleza o de las distintas figuraciones alegóricas contenidas en el concepto de naufragio, en nuestra opinión nada de ello pesó, al menos de un modo decisivo, en el ánimo de Antonio Marqués a la hora de traer tal libro del francés. Creemos, por el contrario, que sus pretensiones se hallaban centradas en otros aspectos más prosaicos, pero también más convenientes para él.

En aras de razonar esta afirmación hemos de reseñar, primeramente, los fragmentos que fueron incluidos en la obra por iniciativa personal de Marqués, y que no aparecían en el original. Entre ellos, aparte de alguna nota al pie de página que ya más atrás hemos transcrito, destaca el añadido incorporado al «Prefacio», así como las «Cortas reflexiones del editor» con las que concluye el tomo III (pp. 379-380), o especialmente el relato adicional agregado al primero de los volúmenes ${ }^{20}$, y en estrecha conexión con él la «Nota y conclusión del Redactor de esta obra» (pp. 319-320) que cierra el V y último de la compilación. Todos esos textos, a pesar de su diferente contenido, parecen apuntar hacia una idéntica finalidad: suscitar la confianza y la intriga en el lector o, lo que es lo mismo, intentar asegurarse potenciales clientes.

${ }^{20}$ No incorporamos aquí a la nómina de los textos originales de Marqués la última narración de la obra, puesto que, con no haber sido traducción, no fue tampoco propia suya, conforme él mismo reconoce desde su mismo título tal y como en su momento trataremos. 
Por lo que atañe al primero de los señalados pasajes - en el que tras desbrozar algunas frases que, aunque ausentes en el prefacio de Deperthes, provenían del «Avertissement de l'éditeur»—, quedaba meridianamente claro en él que la principal intención del traductor estribaba en informar al lector sobre la extensión aproximada del género a adquirir, infundiéndole en cierto modo la tranquilidad de que su coste no se iba a disparar a cuenta de la magnitud del proyecto:

Una y otra se repartirán en cuadernos, en términos que puedan tres de ellos formar cada tomo, para la mayor comodidad, sin que el público pueda temerse que, comprometido ya con la adquisición de los primeros, o se vea precisado a dejar incompleta esta obra, o tenga que llegar a hacerse con un excesivo y costoso número de ellos, pues desde ahora le aseguramos de que toda ella no pasará de unos veinte, a que la tenemos reducida, sin faltar a su completa exactitud, porque en efecto no nos hemos debido extender a más.

El enfoque comercial con que el que aprovechaba Marqués estas líneas quedaba palmariamente en evidencia también cuando avanzaba la fórmula para la venta y promoción de su producto:
Publicada esta primera [entrega o cuaderno] (que como todas es de ocho pliegos) su precio será el de cuatro reales hasta la publicación de la entrega segunda, que pasará ya al de cinco: orden que se observará irremisiblemente con las sucesivas; es decir que se logrará del menor precio tomándola en el término fijo de la pu- blicación únicamente.

Y es que según parece, puede que se desempeñara mejor Marqués en difundir esta índole de ventajas en el destinatario que en persuadirlo con argumentos artísticos o literarios: «deberíamos ahora extendernos aquí en las pruebas del mérito de esta obra; pero esto lo ha de hacer ella misma, con que estaría demás nuestro intento de querer preocupar a favor suyo, y más queremos que el lector por sí mismo lo vea».

De similar manera, enseguida se echa de ver en el segundo de los mencionados añadidos de Marqués, esto es, en las «Cortas reflexiones del editor», que estribaba su principal intención en buscar el asenso y aun la simpatía en el lector por medio de las facilidades, siempre en esa misma línea económica, que le proporcionaba para adquirir el libro: «Sigo mi plan constantemente, tal cual lo propuse en mi primer tomo. Ahorraré a mis lectores todo inútil dispendio a pesar de la utilidad que pudiera provenirme si tuviese yo las miras, harto comunes en nuestros días ${ }^{21} \gg$ (t. III: 379).

${ }^{21}$ De ahí su afán por evitar todo aquello que consideraba superfluo en su narración: «De todos los viajes de Tavernier, que en diferentes idiomas y ediciones han dado materia para volúmenes crecidos, lo contenido en la relación anterior me ha parecido únicamente lo más notable» (t. III: 379). Otra nota al pie, esta vez en el segundo tomo, reiteraba las res- 
Punto de la mayor importancia lo constituye también su declaración de que había procurado en este su trabajo enseñar deleitando a un público, mejor cuanto más amplio: «intento que se disfrute generalmente de su recreo y utilidad», y de cómo en aras de ese interés hubo de renunciar a un léxico más específicamente marinero: «máxima que me ha precisado también a descargar mi estilo, en toda esta obra, de los términos técnicos de la navegación, los que la hubieran hecho impropia y poco inteligible para toda clase de personas» ( $\mathrm{p}$. 380). No obstante, le importaba dejar bien claro que si así lo llevó a cabo, fue por hacerlo más asequible al consumidor, pues su desconocimiento de lo que denomina «nomenclatura naval» lo hubiese de sobra compensado con «la Cartilla marítima y otras obras semejantes (que poseo y manejo), [y que] me hubieran facilitado el medio de sobrecargar infinitamente todas las líneas con voces náuticas ${ }^{22} \gg$ (p. 380).

Con todo, la principal aportación que Marqués realiza en esta colección se sitúa, a modo de colofón, al final del primer tomo, pp. 353-360, bajo el rótulo «Breve noticia del naufragio de la Gabarra Española La Ferrolina en las Costas de la China en 1802»; es decir, los hechos se enmarcaban temporalmente con bien poca antelación respecto de su redacción: «El Comandante General de la escuadra Española, que en el año pasado se hallaba en las islas Filipinas, se resolvió a enviar a Cantón la Gabarra llamada La Ferrolina; para que hiciese allí algunas provisiones y, particularmente, la de bizcocho, de la que más carecía».

Daba también noticia Marqués en ese relato de que los factores de la Compañía de Filipinas habían aprovechado la ocasión para remitir 6.000 pesos fuertes a su oficina de Cantón; sin embargo, la cólera de los elementos no tardaron en cruzarse en su camino: «la gabarra en las costas de China padeció una tempestad de las más terribles», que terminó por hacerla naufragar a unas cuarenta leguas de Macao, a pesar del coraje y competencia profesional de la tripulación hispana: «contando ya el quinto día de una situación tan desesperada, no parecía sino que intentaban las olas a porfía dar a su furor aumento, porque no conseguían vencer la pericia valerosa de nuestros marineros» (t. I: 355$)$.

Enterados de la desgracia los administradores de la Compañía, «enviaron un bajel a aquel paraje con un número suficiente de chapuzadores ${ }^{23} \gg$ (p. 356).

tricciones a que le obligaba su propósito: «Continúa esta relación hasta el naufragio de ambos buques, separadamente, desde el principio del tomo siguiente; pues el método de división adoptado en esta obra no permite más» (t. II: 367).

${ }^{22}$ De todos modos, sí que resulta evidente algún conocimiento de Marqués en el manejo del lenguaje marinero; por ejemplo, cuando mantiene en su traducción la palabra «equipaje» (del francés «équipage») para denominar a la tripulación, o al llamar «urca»a un cierto tipo de embarcación.

${ }^{23}$ Aunque el término «chapuzador» no figuraba en el Diccionario de Autoridades, sí que se incluía en él la palabra «chapuzar»: «Meter y sacar repetidas veces, y con ligereza, 
Los chinos, por su parte, internaban a los náufragos en el país para quedarse con la carga del buque, de forma que «cuando llegaron allí los buzos ${ }^{24}$ enviados por los Factores de la Compañía, solamente recogieron unos ochenta mil pesos, que eran los únicos que había dejado la bárbara avaricia». Aunque se enderezó la situación, al cabo, cuando las autoridades hicieron devolver el dinero y los géneros rescatados del mar; si bien no renunciaba el autor a mantener la expectación dejando en el aire el resultado definitivo de la investigación posterior, acerca de «si las justicias del país habían sido cómplices o noticiosas, a lo menos, del robo, sin haber hecho los debidos esfuerzos para estorbarlo».

Concluía el episodio Marqués y Espejo muy en su estilo, reincidiendo, por un lado, en el interés por enfatizar el carácter que de tanta actualidad poseía el conflicto, de final incierto aún: «Tal era el estado de este asunto a últimos del año pasado de 802, cuando se recibieron las noticias expuestas hasta aquí. La Compañía de Filipinas conserva la esperanza bien fundada del recobro de sus capitales» (p. 359). Y, por otro, complaciéndose en el sosiego por la conservación de un capital que no había de perderse en ningún caso (que «en nada perjudicaría a los interesados»), pues viajaba siempre asegurado a través de unas reservas que atesoraban «en sus cajas de Manila y Cantón más de dos millones de pesos fuertes».

Merecen destacarse de este suceso narrado por Antonio Marqués dos puntos que pueden ser susceptibles de arrojar alguna luz sobre su desconocida personalidad. Por un lado, y en consonancia, con la anteriormente reseñada inquietud por la preservación de los bienes materiales, se muestra evidente que, lejos de la crueldad extrema de la naturaleza o de la determinación, en ocasiones épica de los personajes, que caracterizaban las aventuras transcritas por Deperthes, el ingrediente principal del traductor español lo constituye el posible expolio de la mercancía a que se veía sometido un buque de su misma nacionalidad. Por otra parte, a diferencia del resto de las historias compiladas, esta de Marqués dejaba el final abierto, manteniendo el suspenso en los destinatarios, a fin de que quedaran, durante el resto de las entregas, pendientes y deseosos de conocer el resultado final de sus compatriotas:

Careciendo hasta ahora de noticias más individuales y circunstanciadas de este naufragio no me es posible el enterar a mis lectores de las particularidades que desearían para la satisfacción de su curiosidad; pero espero podérselas dar algún

alguna cosa en el agua u otro cuerpo líquido, y de ordinario de cabeza, como hacen los nadadores» $(1729$, t. II).

${ }^{24}$ El Diccionario de Autoridades definía «buzo», como «el hombre que con habilidad de gran nadador, deteniendo por largo espacio el aliento, saca del fondo del mar o de los ríos las cosas sumergidas en el agua [...]» $(1726$, t. I). No sabemos si tales vocablos «chapuzador» y «buzo» formaban parte de esa Cartilla marítima o de otras obras similares que Marqués manifestaba tener a su alcance. 
día, cuando, sin interrupción del orden cronológico adoptado en esta obra, les vuelva yo a hablar de él (t. I: 355-356).

Pero, a pesar de tal declaración de intereses, lo cierto es que en nunca más volvió a tocar el tema, ni siquiera para informarnos sobre su desenlace final; aunque, consciente de que había faltado a su compromiso, Antonio Marqués aludió a esa cuestión en la última de las adiciones que hemos dicho agregó a la colección: «Nota y conclusión del Redactor de esta obra», si bien únicamente lo hizo para explicar su silencio: «por alguna de mis promesas hechas al lector, tanto en el contenido del número último del primer tomo como en otros, se echará de ver fácilmente que ofrecí mayor extensión sobre algunas relaciones, y particularmente en la del número citado, sin que se haya verificado su cumplimiento» (t. V: 319). Excusaba Marqués su conducta en la dificultad de hallar documentos correspondientes a percances marítimos hispanos, a la vez que formulaba, ciertamente que con tibieza, un propósito de enmienda para remediar esa carencia: «Por esta causa difiero, mas no desisto de la idea de perfeccionar mi obra con un suplemento respectivo a nuestros naufragios nacionales» (t. V: p. 320).

$\mathrm{Y}$ terminaba, finalmente, el autor estableciendo una conexión entre esa intención y el éxito que declaraba haber alcanzado entre el público la obra, como si de algún modo se diera a entender que mucha parte de ese aplauso se había cimentado con las vicisitudes del barco español: «no omitiré diligencia alguna para adquirírmelos [los materiales necesarios para la realización de dicho trabajo], correspondiendo así agradecido a la lisonjera aceptación con que el público ha honrado esta obra ${ }^{25}$ » (ibídem).

A pesar de esa pretendida aspiración suya, Antonio Marqués y Espejo no volvió a retomar luego ya nunca el asunto. Y entre unas cosas y otras, la inclusión del mencionado relato de La Ferrolina más parece una añagaza de comerciante avispado que arrebato de celo patriótico, pues posiblemente lo utilizó solo a modo de cebo para dejar intrigados y expectantes a sus lectores, y persuadirlos de esta forma para que se suscribieran a la colección. En este sentido, no debemos pasar por alto tampoco la inscripción con la que se abría cada tomo en la hoja que seguía a la portada: «Este y los demás ejemplares de las obras de su autor irán sellados y rubricados por él mismo; y se hallarán en la Librería de su despacho, calle de Jacometrenzo [sic], núm. 8, hacia la plazuela de Santo Domingo»; esto es, con técnicas modernas hasta para hoy en día, ya firmaba ejemplares nuestro buen presbítero hace más de dos siglos,

${ }^{25}$ El Memorial Literario ( $\mathrm{n}^{\circ}$ 53: 281-285) se hacía eco de esa confirmación de Marqués, a la postre estéril: «Con este tomo concluye la historia de los naufragios célebres, pero el traductor cumpliendo lo que prometió en el prólogo ofrece publicar algunas adiciones, aunque tardará algún tiempo en verificarlo por lo difícil que dice le es adquirir los documentos y noticias que necesita» (p. 285). 
especificando que lo hacía en su tienda, de la cual se cuidaba de facilitar el domicilio.

Además del mentado de La Ferrolina, añadió Marqués a su conjunto de episodios, según antes hemos aludido de pasada, otro más que, aunque ajeno al repertorio de Deperthes, tampoco procedía de la minerva de nuestro traductor; nos estamos refiriendo a, precisamente, el último de la colección, al que Antonio Marqués nombró del siguiente modo: «Relación del naufragio del bajel inglés El Aquiles, en un pequeño puerto de las costas de América. Rapto y abandono de Yarico, joven americana, por Inkle, y carta de la misma a su pérfido amante». Este largo rótulo continuaba con la mención de las fuentes del propio relato: «Recopilado todo del Diario de los sabios, del Correo de Cádiz y del Semanario de Salamanca del martes 27 de Mayo de $1800^{26} \gg$ (t. V: 301).

Como de la primera parte del título se desprende, se traía aquí la historia de la traición infringida por Tomás Inkle a la india Yarico, quien habiéndole salvado a aquel la vida, y hallándose dispuesta a dejarlo todo por permanecer a su lado, acaba finalmente siendo vendida como esclava por él. Llama particularmente la atención que en esta relación, ausente en Deperthes, se dé cabida a un lance tratado de forma sumamente emotiva y sensible, tanto en el tema elegido: la traición en el amor y la pérdida de la libertad, como por el léxico adoptado; todo ello en un marco muy escasamente relacionado con los naufragios, pues el que aquí acaece se despacha en un par de líneas, y funciona solamente como excusa para plantear el escenario en el que se desarrollará el posterior conflicto.

Aunque, lamentablemente, no hemos podido examinar ninguno de los tres periódicos de los que dice Marqués haber tomado esta narración, de las palabras vertidas por el Memorial Literario parece deducirse que la misma no debió sufrir muchas variaciones tras el paso por su péndola: «Esta historia se ha publicado en varias obras, por lo cual no nos hemos detenido en referir sus circunstancias» ( ${ }^{\circ}$ LIII: 285). Desconocemos, sin embargo, si el tipo de vocabulario, bastante más intimista que el del resto de relatos, singularmente por lo que atañe a la carta que Yarico escribe a su cruel y felón amante, en la que abundan las interrogaciones, exclamaciones, frases entrecortadas, puntos suspensivos, suspiros, lamentos, etc., se hallaba ya en los textos en los que bebió Marqués, o si por el contrario fueron producto de su propia cosecha.

De una u otra forma, lo cierto es que, si bien, carecemos de una respuesta para ello, sí que damos por seguro, por lo poco que sabemos de él, que si finalmente terminó por insertar en su colección este género de literatura era porque se hallaba persuadido de que no habría de venirle mal al negocio.

${ }^{26}$ No podemos dejar pasar la mencionada alusión a un ejemplar de 1800 del Semanario de Salamanca sin recordar las dudas que existían hasta hace bien poco acerca de si se había publicado en ese año el citado Semanario (vid. Pedro Álvarez de Miranda 2011: 197-203). 


\section{LA Historia de los NaUfRagios EN LA PRENSA DE LA ÉPOCA}

Hemos hablado hasta aquí de la contribución personal de Marqués y Espejo a la obra, más allá, desde luego, de la de llevar a cabo su traducción; sin embargo, existen otros textos relacionados estrechamente con la misma que creemos - entre otras cosas por la forma en que figuran redactados- que salieron también de su pluma, si no en su versión definitiva, sí al menos a modo de guion o plantilla, como fueron los casos de muchos de los anuncios publicados en la Gaceta de Madrid y en el Diario de Madrid, particularmente de aquellos más significativos. Así, con ocasión de la aparición del primer cuaderno, se dejaba constancia en la Gaceta de Madrid de 1 de julio de 1803 ( ${ }^{\circ}$ 52: 568), junto con esa intención del prodesse et delectare, del orgullo de Marqués hacia su trabajo: «Esta obra, que puede llamarse general en toda la Europa, porque sus naciones cultas la poseen, aunque con variedad en el modo de su edición, faltaba a la nuestra; por lo que muy seguros de su recreo e instrucción la ofrecemos al público». En similares términos había amanecido el Diario de Madrid el día anterior ( $\mathrm{n}^{\circ} 181,30$ de junio: 727$)$ : «no se ha omitido diligencia alguna para hacerla digna de su mérito original, harto conocido por las Naciones más cultas de la Europa. Deseosos de que sea extensivo también a la nuestra, en cada mes se publicará un cuaderno». En ambos casos, y como no podía ser de otro modo, se proclamaban bien claramente aquellos consabidos puntos del «Prefacio» que pretendían convencer al hipotético comprador tanto del gasto moderado que supondría la adquisición de toda la colección como del ahorro en cada ejemplar si no se demoraba en conseguirlo, así como, por supuesto, los locales en los cuales se vendía.

A la altura de octubre de 1803 parece que Marqués ya podía facilitar a su público el número exacto de entregas de las que habría de componerse la colección (aunque finalmente resultó equivocada la cifra), circunstancia que sabemos por la Gaceta de Madrid del día 14 de ese mes (nº 83: 896): «con arreglo al primer anuncio de su editor constará de 17 entregas solamente ${ }^{27} \gg$.

${ }^{27}$ En relación con este punto, hemos de recordar que en el «Prefacio» e, igualmente, en los mencionados anuncios de la prensa madrileña dando primera noticia de su existencia, se significaba que el total de la compilación no pasaría de unos veinte cuadernos «a que la tenemos reducida». Tras asignar esta cifra, Marqués intercalaba en el mentado «Prefacio» un fragmento traído del «Avertissement de l'éditeur», donde se revelaba que habían sido desechadas, por diversos motivos, otras muchas de estas peripecias marinas de esta índole: «nos hemos separado de otras que, aunque harto interesantes, hubieran llegado a formar por sí solas volúmenes enteros». Es decir, Marqués no se estaba refiriendo ahí a la circunstancia de prescindir de los tres relatos de Deperthes que finalmente no transcribió, sino que se limitaba a decir lo mismo que el «éditeur». Posteriormente, en esas fechas de mediados de octubre de 1803, en que ya habría decidido no trasladar dichas tres aventuras, pudo llegar Marqués a esa estimación de los 17 cuadernos, equivalentes fácilmente a más de 200 pp. en la edición española. 
Como, finalmente, los cuadernos se quedaron en quince, ignoramos qué tenía pensado Marqués en ese otoño de 1803 para que le fallaran así los cálculos, pues de hecho cada tomo hasta ese momento se iba componiendo, invariablemente, de tres de dichas entregas, por lo que lo más lógico sería contar con quince o con dieciocho cuadernos, dependiendo si tenía previsto cinco volúmenes, o seis. Lo más probable es que a medida que avanzaba en su traducción, Marqués iba recortando del original cada vez más de lo que en un principio había pensado ${ }^{28}$.

No será hasta últimos de febrero de 1804 cuando se dé a entender la cifra exacta de folletos que formarán la colección: «El cuaderno 14 de la Historia general de los naufragios, penúltimo de toda la obra» (Gaceta de Madrid de 28 de febrero, $\mathrm{n}^{\mathrm{o}}$ 17: 188, y en similares términos el Diario de Madrid de 7 de marzo de 1804, n 67: 266); y de nuevo hallamos aquí rastro de las inquietudes comerciales de nuestro traductor, puesto que en la Gaceta de Madrid podemos leer:

A fin de que los expendedores que se hayan atrasado en recoger los cuadernos no sufran ningún perjuicio, se les advierte que, desde esta publicación hasta el cumplimiento del término de un mes del siguiente cuaderno último, se darán sueltos solamente, pues después el editor dispondrá de ellos a su arbitrio para completar sus ejemplares.

Aunque de forma más breve, también en el Diario de Madrid de 7 de marzo, antes citado, se daba cuenta de este mismo procedimiento a seguir por el editor.

Y así llegamos, por fin, a la postrera entrega, anunciada en la Gaceta de Madrid del 16 de marzo de 1804 (n 22: 248). Obviamente Marqués no podía desperdiciar la ocasión para repasar las diferentes condiciones y precios, extras incluidos, relativos al libro:

Toda la obra, que consta de 5 tomos en octavo, se dará en dichas librerías a 70 rs. en papel (siempre que se tomen los juegos pasando de media docena), a 75 rs. a la rústica y a 85 en pasta por menor, pues también se hará en la encuadernación la mayor equidad, llevándose desde la media docena arriba. En dichas librerías se venden separadas para esta obra también a real las 6 estampas».

Por otra parte, esa noticia del fin de la labor de D. Antonio sí que se manifiesta ahora de manera bien distinta, respecto a la Gaceta, en el Diario de Madrid de 10 de abril de ese 1804 (nº 101: 400-401). El anuncio, más largo

28 De haber mantenido en su transvase la proporción de páginas dedicadas al primer volumen de Deperthes (366 pp., sin contar el índice), la versión de Marqués (601pp.) habría sobrepasado las 2000 pp., pero, como la tala fue in crescendo, al final las aventuras plasmadas por el francés en tres volúmenes quedaron reducidas aproximadamente a $1800 \mathrm{pp}$. en la tirada de cinco tomos en castellano, sin computar los dos episodios ausentes en Deperthes. 
que los habituales, ponía de relieve que la obra iba destinada a las almas sensibles, y que, fundamentada en la verdad, podía proporcionar consuelo a los desgraciados, así como una especie de manual de supervivencia para todos aquellos que algún día pudieran experimentar una suerte similar a la sufrida por los protagonistas de esta galería de naufragios. Sin embargo, todos estos conceptos no eran genuinos de Marqués, sino extractados del «Preface» de Desperthes, según ya más atrás hemos dejado anotado.

Además, en aras de la prosperidad del negocio, pero esta vez con palabras propias y sin apoyo alguno en su fuente original, no dejaba nuestro traductor de elogiar el producto que intentaba vender, sin olvidarse de proclamar en ningún momento ese afán que le guiaba siempre de llegar a cuantos más lectores mejor, y de procurar, junto a su agrado, su provecho:

Como su editor se propuso en ella desde los principios llegar a hacer su lectura general, y que toda clase de gentes pudiese lograr de su delicioso recreo, de su instrucción y utilidad, ha empleado de intento en su estilo una elocución familiar y común, despojada de los términos técnicos, propios de la facultad náutica (p. 400).

Al presbítero Antonio Marqués tampoco le habría de venir mal, de cara a ese mismo interés mercantil, predicar la eficacia de la religión y las bondades morales contenidas en el libro, contraponiéndolo de ese modo a toda aquella otra barahúnda de títulos que, en su opinión, nada fructífero podían aportar al destinatario:

En estos tiempos en que se difunden las luces con tanta generalidad, y en que la misma aplicación a los buenos libros hace que se desaprueben los marcados con el sello de la frívola inutilidad, no pueden menos de ser bien recibidos los cinco tomos de esta obra, donde se describen en lo físico y moral algunas naciones de los países más remotos; se encuentran varios sacrificios, hechos y dictados por el bien de la humanidad; se ven los consuelos con que la religión sostiene en medio del abandono general, y se registra, en fin, el nuevo ámbito de unos sucesos verdaderos y auténticos (pp. 400-401).

Fuera de la Gaceta y del Diario de Madrid, pero prosiguiendo bajo la misma jurisdicción de la pluma de Marqués, el Almanak Literario, editado por él, daba cumplida cuenta de la puesta a la venta de su recopilación de naufragios, con algunos leves matices respecto de los anuncios anteriores, aunque enfocados como siempre, eso sí, a la esfera comercial, como por ejemplo la referencia a que los cinco tomos son «harto voluminosos», o la precisión que se detalla tras consignar el importe de los mismos: «sin estampas; pues la colección de ellas añade 6 rs. a su precio» (1804: 233).

Y por el mismo importe que en este de 1804, pero con las seis estampas dichosas incluidas, aún se seguían ofertando en el año 1815 los cinco tomos en octavo, conforme recoge la Gaceta de Madrid del 27 de junio ( ${ }^{\circ}$ 77: 728). En 1824, en un catálogo de esa fecha de la librería de Fuentenebro, señala 
Morán Orti (2009: 184) que se mencionaba la existencia de «cinco [estampas] que adornaban la Historia de los Naufragios de Antonio Marqués y Espejo, libro impreso por Repullés en 1804». Y gracias a la relación de «Novelas que se hallan de venta en la misma librería de Mompié», estampada al final de una reedición de Anastasia, o la recompensa de la hospitalidad, sabemos que la obra, al menos en Valencia, aún se seguía vendiendo en 1826 (Marqués y Espejo, 1826: h. s. n.).

Sin embargo, no todo fueron parabienes ni amables palabras en las publicaciones periódicas cuando se hicieron eco de la labor de Marqués. Testimonio de ello lo constituye el Memorial Literario, especialmente en lo atinente a sus comentarios sobre el tomo inaugural de la colección, del que aparte de algunos defectos que en todo caso habrían de serle imputados al autor francés - como por ejemplo la reiteración en las causas de las desgracias: exceso de frío, abundancia de nieve, etc.- opinaba que «la traducción es mala, y aun malísima, y la edición incorrecta» ( $\mathrm{n}^{\circ}$ XLVIII: 99). No obstante, la escasa simpatía mostrada por este periódico no resultó óbice para que sus páginas le dedicaran una atención generosa, entreteniéndose de modo casi exclusivo en resumir cada una de las aventuras ${ }^{29}$.

Por otro lado, este mismo $\mathrm{n}^{0} \mathrm{~L}$ del Memorial Literario se hacía eco (pp. 175-176) de la aparición de la Biblioteca geográfica o colección de Viajes para la juventud. Escrita por el Señor Campe y traducida por Don Juan Corradi, y al final del anuncio, con motivo de señalar que tanto en esa obra como en el tomo II de Marqués se trataban el viaje a Spitzberg y a la Nueva Zembla y las peripecias de cuatro marineros rusos, se lanzaba el siguiente varapalo para con la labor de Marqués: «pero aquí tendrán los lectores que quieran ver esta relación con toda extensión el placer de hallarla bien traducida» (p. 176). Reincidiendo de esta forma el Memorial Literario, una vez más - contra el parecer que hemos visto exhibía el censor Pedro Estala-, en las deficiencias de Marqués y Espejo para trasladar este libro al castellano ${ }^{30}$.

${ }^{29}$ Así el primer volumen de Marqués apareció reseñado en el indicado $\mathrm{n}^{\circ}$ XLVIII: 98102, el segundo en el $n^{\circ}$ XLIX: $129-139$, el $3^{\circ}$ en el $n^{\circ}$ L: 161-167; el $4^{\circ}$ en el ${ }^{\circ}$ LI: 194-196, y el $5^{\circ}$ en el $n^{\circ}$ LIII: 281-285. Esta relación ya había sido consignada por Arturo Morgado en su citado estudio (2013: 245, n. 39). Por entre el habitualmente tupido rechazo por parte del Memorial Literario a la versión de Marqués, se abre paso en ocasiones concretas una visión más benigna: «La relación del Número $\mathrm{I}^{\circ}$ [del tomo II] presenta bastante interés y curiosidad, por lo que merece que nos detengamos en ella» ( $\mathrm{n}^{\circ}$ XLIX: 129). «Una de las relaciones más interesantes que contiene este tomo $\left[5^{\circ}\right]$ es la de las desgracias que sufrió la Señorita de Bourk» [...]. «También es muy notable la relación del número $6^{\circ}$, en que se cuenta el hambre extraordinaria que padeció la tripulación del bajel americano El Peggy el año de $1765 »$ ( $\mathrm{n}^{\mathrm{o}}$ LIII: 281 y 284 ).

${ }^{30}$ Cierto es que la versión castellana de Antonio Marqués contiene algunos galicismos, presentes incluso en fragmentos propios suyos, no traducidos; pero creemos que ni su cantidad ni su gravedad le hacen acreedor a una desabrida condena. 
De cualquier modo, aun de bastante complacientes con el trabajo de Marqués pudieran calificarse las valoraciones del Memorial Literario si entramos a compararlas con las vertidas por El Regañón General o Tribunal Catoniano de Literatura, Educación y Costumbres de 11 de febrero de 1804 ( n $^{\circ}$ 12: 93-94), donde salada y ocurrentemente se comentaban los tres primeros cuadernos de la Historia de los naufragios, «que está publicando (no sé si como autor o traductor) el Doctor Don Antonio Marqués y Espejo, Presbítero, \&. \&., por quien salen firmados, sellados y marchamados, y en los cuales se encuentra también el más desgraciado naufragio que ha padecido la lengua castellana» (p. 93). Su lectura apuntaba el narrador del artículo que le produjo luego tal mal sueño, que en él un amigo suyo pretendía arrojar aquellos papeles a la chimenea al grito de «esto no debe correr, pues es una vergüenza que el siglo XIX se estropee así nuestro idioma» (ibídem); por lo cual se determinó, en fin, a no adquirir el resto de la obra, ante el temor de que «me causen tal pesadilla, que alguna noche me haga cargar con mi cama y demás trastos, y precipitarme en la cueva de mi casa creyendo que es la del navío. ¡Jesús, tiemblo de pensarlo! Dios libre a vmd. de leer tales obras, por los daños que pueden ocasionarle» (p. 94).

\section{CONCLUSIONES}

Conforme hemos visto a través del análisis de esta traducción de Antonio Marqués, fácilmente se colige que de su ánimo se desprendía una muy potente tendencia hacia la utilidad. De un lado, para con los lectores, a los que se intentaba enriquecer en su conocimiento mediante datos de otras latitudes y culturas $^{31}$; y de otro para sí mismo, pues con constancia buscaba extraer el mayor provecho económico de la venta de sus libros. En un par de líneas de uno de sus prólogos patentiza bien gráficamente y sin tapujo alguno ese toma y daca: «iDichoso yo, si con esta obra, me procuro algunos reales! Y venturoso tú, Lector benévolo si consigues un recreo útil de nuestras producciones» (1802: VII). Y, por si no quedase suficientemente claro, anuncia, al final de ese mismo proemio que desea rematar su «obrilla» con el siguiente epigrama: «No deseo que me aprecien, sino que me compren» (XII).

Fruto de ese talante pragmático, alumbrará su pluma en aquellos primeros años del siglo XIX, y aún antes ${ }^{32}$, obras instructivas y didácticas, así para be-

${ }^{31}$ Así puede afirmar Morgado García que «gracias a sus relatos los lectores hispanos tuvieron la ocasión de familiarizarse con lugares como Nueva Zembla, Groenlandia, la bahía de Hudson, Spitzbergen o Kamtchatka, con pueblos como los lapones o los esquimales, con animales como los osos polares, las vacas marinas, y con fenómenos meteorológicos inauditos como las auroras boreales o el sol de medianoche» (2013: 247).

${ }^{32}$ Pues ya desde la primera obra de la segura adscripción de Antonio Marqués y Espejo, compuesta en 1793 y titulada El perfecto orador, se facilitaban una serie de técnicas e 
neficio del alma, caso de la Antorcha mística (traducida del latín), como eficaces para desenvolverse por el mundo: ya enseñando a escribir todo género de cartas en la Retórica epistolar, ya compendiando al sabio benedictino orensano con el Diccionario feijoniano, o procurando, en fin, una más fluida información entre publicaciones literarias y potenciales lectores, con el Almanak literario, Manual utilísimo para los comerciantes de libros y apasionados a la literatura.

En ese afán por atraerse el favor del público hemos de reseñar que Antonio Marqués eligió un tema muy a propósito al trasplantar a nuestro idioma este asunto de los naufragios, muy de moda desde la publicación del Robinson Crusoe de Daniel Defoe, que, como apunta Ana Rueda (2001: 427), «se convierte en planilla para toda esa progenie de náufragos ilustrados» y muy apreciado, ciertamente, por el público ${ }^{33}$. Por otra parte, supo el autor poner muy bien su libro en valor, pues no solo colocó el énfasis en su propio contenido, o en su significado cultural, refiriendo, por ejemplo, que en él encontraría el lector lo mismo solaz y recreo que fructíferas enseñanzas, o subrayando el mérito de que se hallaba traducido en todas las naciones cultas de Europa; sino también potenciando su vertiente más puramente material, mediante la personalización de cada uno de los ejemplares que se compraban en la librería familiar de Espejo, calle de Jacometrezo, en los que, como en el resto de obras suyas allí expendidas, figuraba estampada su firma.

A ese mismo respecto, debemos tener también presente que, además de intentar sacar el mayor partido de los anuncios de la obra insertos en la Gaceta de Madrid y en el Diario de Madrid, en cuya confección de al menos los más importantes creemos que intervino de forma personal, se cuidó de lanzar ofertas del producto que despachaba, brindando a menor precio, durante un determinado período de tiempo, cada nuevo cuaderno que salía de la imprenta; aderezando todos estos recursos con la continua proclamación de un sentimiento de leal desvelo por su clientela, a la que hacía ver, incluso, que anteponía los intereses de ella a los suyos propios como autor: «Ahorraré a mis lectores todo inútil dispendio a pesar de la utilidad que pudiera provenirme» («Cortas reflexiones del editor», t. III: 379 ).

En el manejo de este género de técnicas, juzgamos que devino en toque magistral la inserción en su primer tomo del suceso padecido por una embarcación hispana en las lejanas costas del sur de China, puesto que la introducción en la obra de protagonistas españoles a buen seguro que la acercó más al público y contribuyó a que la adquiriera un mayor número de compatriotas, de

ideas, ejemplificándolas con el texto de un autor francés, para beneficio de quien tuviera que hablar en público, y de modo particular para los sacerdotes que se dedicaran a predicar.

${ }_{33}$ Monique Brosse menciona algunos de los secretos del éxito de este género de literatura: «Les histoires des naufrages entretiennent avec l'héroïsme, ou, du moins, le courage, des rapports sobres et évidents. La sauvagerie de la nature, la nécessaire lutte des professionnels de la mer contre elle, s'y inscrivent en clair» (1972: 114a). 
los cuales muchos de ellos quizás permanecieron expectantes durante el resto de la colección, comprando cuaderno tras cuaderno, y aguardando pacientes el desenlace final de aquella peripecia que el escritor les había prometido ${ }^{34}$.

Aunque, como ya sabemos, tal resolución del conflicto nunca llegó. Según parece, las ventas funcionaban bien, y la prosecución en aquel tema le suponía a Marqués una serie de complicaciones e inconvenientes que, por lo visto, no le traían cuenta. Oportunidades para ello tampoco habrían de faltarle más adelante, puesto que solo un par de años más tarde tradujo otro libro de expediciones a través del globo y periplos de toda índole: Elección de viajes modernos, en los que muy bien pudo haber tenido encaje la conclusión de dicho episodio ${ }^{35}$.

\section{FUENTES}

Catalina García, Juan (1899). Biblioteca de escritores de la provincia de Guadalajara y bibliografia de la misma hasta el siglo XIX. Madrid: Sucesores de Rivadeneyra.

Deperthes, Jean Louis Hubert Simon (1788-1789). Histoire des naufrages. París: Née de la Rochelle.

Marqués y Espejo, Antonio (1793). El perfecto orador. Valladolid: Viuda e Hijos de Santander.

Marqués y Espejo, Antonio (1802). Desahogos líricos de Celio, dedicados al dios Apolo. Madrid: Imprenta de Repullés.

Marqués y Espejo, Antonio (1803). Retórica epistolar o arte nuevo de escribir todo género de cartas misivas y familiares [...]. Madrid: Imprenta de Cruzado.

Marqués y Espejo, Antonio (1803-1804). Historia de los naufragios [...]. Madrid: Imprenta de Repullés.

Marqués y Espejo, Antonio (1804). Almanak literario. Manual utilísimo para los comerciantes de libros, y apasionados a la literatura [...]. Madrid: Gómez Fuentenebro.

Marqués y Espejo, Antonio (1806). Elección de viajes modernos que contiene los sucesos más útiles y agradables, relativos a las expediciones y principales descubrimientos hechos alrededor del mundo, y la descripción de los usos y costumbres de los pueblos. Madrid: Gómez Fuentenebro (t. I) y Repullés (t. II, III, IV y V).

Marqués y Espejo, Antonio (1826), $1^{\mathrm{a}}$ edición: 1818. Anastasia, o la recompensa de la hospitalidad. Anécdota histórica de un casto amor contrariado. Valencia: Ildefonso Mompié.

${ }^{34}$ El concepto de «cebo» para conseguir lectores ya lo había manejado Antonio Marqués en la Retórica epistolar (1803: 3-4), donde precisamente utiliza esa concreta expresión al reconocer que se tomó la molestia de traducir a autores extranjeros, tales cuales Bussy, Sévigné, Maintenon, Racine, Fleury, etc., porque «no solo servirán de cebo a la curiosidad de los sujetos más instruidos, sino que toda clase de personas procurará imitar».

${ }^{35}$ Los cinco volúmenes de la Elección de viajes modernos (1806) se publicaron dentro de la Biblioteca Selecta de las Damas. Segunda clase. Geografia y viajes (tomos IV-VIII); $\mathrm{y}$, aunque se silenció en ellos el nombre del traductor, conocemos su identidad gracias a la Gaceta de Madrid de 19 de junio de 1807, $\mathrm{n}^{\mathrm{o}}$ 52: 625-626, y a su mención por parte de Demerson (1976: 25), si bien denomina la obra como Colección de viajes modernos, al igual que lo había hecho la Gaceta de Madrid de 3 de mayo de 1827, n 53, pág. 212b. 


\section{BIBLIOGRAFÍA CITADA}

Aguilar Piñal, Francisco (1991). Introducción al Siglo XVIII. Madrid: Ediciones Júcar.

Álvarez Barrientos, Joaquín (1991). La Novela del Siglo XVIII. Madrid: Ediciones Júcar.

Álvarez de Miranda, Pedro (2011). «René Andioc tenía razón: la Continuación del Semanario de Salamanca (1800)», Cuadernos dieciochistas. 12, pp. 197-203.

Arenas Cruz, María Elena (2003). Pedro Estala, vida y obra. Una aportación a la teoría literaria del siglo XVIII español. Madrid: CSIC.

Ballesté, Jacques (1998). «Algunas consideraciones sobre el concepto de naturaleza en la novela a principios del siglo XIX», en Yvan Lissorgues y Gonzalo Sobejano (coord.), Pensamiento y literatura en España en el siglo XIX. Idealismo. Positivismo. Espiritualismo. Toulouse: Presses Universitaires du Mirail, pp. 36-44.

Barrio Moya, José Luis (2005). «La librería de don Timoteo María Gálvez, un liberal toledano en el Madrid de Fernando VII (1820)», Anales Toledanos. 41, pp. 345-364.

Brosse, Monique (1972). «Littérature marginale: les histoires des naufrages», Romantisme. 4, pp. 112-120.

Demerson, Paula de (1976). Esbozo de biblioteca de la juventud ilustrada (1740-1808). Oviedo: Catedra Feijoo - Universidad de Oviedo.

Fénelon, François de Salignag de la Mothe (1932) [1699]. Suite du IV libre de l'Odyssée ou les Aventures de Télémaque, fils d'Ulysse. Citamos por Aventuras de Telémaco. Hijo de Ulises. Madrid: Espasa-Calpe.

Froldi, Rinaldo (1984). «Apuntaciones críticas sobre la historiografía de la cultura y de la literatura españolas del siglo XVIII», Nueva Revista de Filología Hispánica. XXXIII, 1, pp. 59-72. Accesible en: <http://www.cervantesvirtual.com/nd/ark:/59851/bmcx34s2>

Guillén Marcos, Esperanza (2004). Naufragios: imágenes románticas de la desesperación. Madrid: Siruela.

Morán Orti, Manuel (2009). «La imprenta y librería "Qué fue de Fuentenebro": un modelo empresarial y un programa editorial a finales del Antiguo Régimen», Ayer. 74 (2), pp. 165-190.

Morgado García, Arturo (2013). «La imagen del naufragio en la España del siglo XVIII», en El mar en la historia y en la cultura, ed. Alberto Gullón Abao, Arturo Morgado García y José Joaquín Rodríguez Moreno. Cádiz: Universidad de Cádiz, pp. 229-248.

Pérez-Mallaína Bueno, Pablo Emilio (1997). Naufragios en la Carrera de Indias durante los siglos XVI y XVII. El hombre frente al mar. Sevilla: Editorial Universidad de Sevilla.

Rueda, Ana (2001) Cartas sin lacrar. La novela epistolar y la España Ilustrada, 1789-1840. Madrid: Iberoamericana - Vervuert.

Sánchez-Blanco, Francisco (1986). «Política y moral en la tragedia ilustrada: Los Teseides, o El Codro de Cándido María Trigueros», Revista de Literatura. XLVIII, 95, pp. 35-49.

Fecha de recepción: 29 de noviembre de 2016.

Fecha de aceptación: 30 de marzo de 2017. 